\title{
Influence of local exhaust ventilation parameters on the quality of the room's air environment
}

\author{
Alexey Shashin ${ }^{1}$, Roman Sheps ${ }^{1}$, Dmitry Lobanov ${ }^{1, *}$ and Alexander Mershiev ${ }^{1}$ \\ ${ }^{1}$ Voronezh State Technical University, 20 let Oktyabrya Str., 84, Voronezh, 394006, Russia
}

\begin{abstract}
The article considers the influence of local exhaust ventilation parameters on the quality of the room's air environment. On the basis of experimental studies, dependencies were established that determine the effect of mass transfer processes occurring in the local exhaust ventilation shelter on air quality in a room working area. The influence of a flat plate installed in the lower part of technological opening of a shelter that prevents incoming air movement from a room to a source surface of convective jet is determined. This measure made it possible to reduce the air velocity above surface source and the amount of harmful emissions by 2.5 times, as well as to reduce their flow into a room through an opening a shelter. These measures allow to reduce energy costs for room ventilation and improve air quality in the serviced room.
\end{abstract}

\section{Introduction}

Local exhaust ventilation, in contrast to General exchange ventilation, more effectively provides standardized air quality in working area of a room according to sanitary and economic indicators.

The reception of gaseous and vapor harmful chemical emissions from their sources is the most significant part of local exhaust ventilation. It forms the processes of formation of harmful secretions, removing them from the premises and reducing the flow of harmful substances into the room. The effectiveness of local exhaust ventilation is most determined by the amount of harmful emissions caught and reduction of their flow entering a room. Among the devices for local suction of harmful chemical secretions (HCS), the most effective are Cabinet-type shelters. A Cabinet shelter for suction of HCS formed over a heated surface was investigated. Assuming the tightness of enclosure structures of the shelter, the main place where harmful emissions enter the room is an open doorway of the Cabinet for loading and unloading items, as well as performing other technological operations. Harmful emissions through an opening of a shelter due to turbulent diffusion enter a room against oncoming air flow [1]. The task was to establish measures that reduce harmful secretions formation and their penetration into a room.

The solution of the problem was achieved by performing analytical and experimental studies of mass transfer and aerodynamic processes that increase the efficiency of local

*Corresponding author: LDV-36@mail.ru 
exhaust ventilation.

\section{Experimental}

The schematic diagram and parameters of a Cabinet-type shelter with an upper side suction of the gas-air mixture are shown in figure 1. Side suction is used when close alignment hole exhaust over heated source of harmful emissions is not achieved for technological reasons and when it is necessary to increase the removal of hazards from workers breathing zone [2].

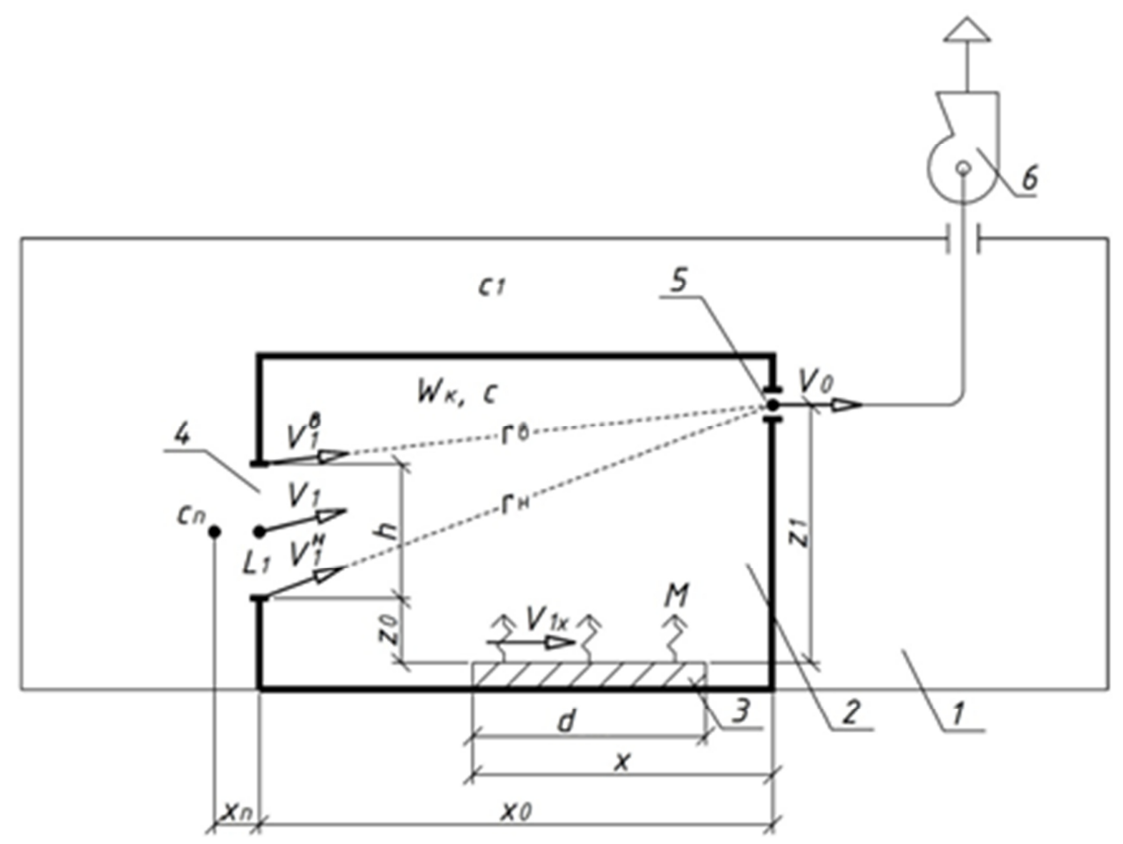

Fig. 1. Schematic diagram and parameters of the local exhaust ventilation: 1-room, 2-shelter, 3 source of harmful emissions, 4-technological opening of the shelter, 5- suction hole of gas-air mixture, 6-fan.

In the studied scheme of a shelter, a slit suction of gas-air mixture is adopted as the most effective in comparison with other hole designs.

Accepted designations: L1 - consumption of air coming from a room to a shelter, $\mathrm{m} 3 / \mathrm{s}$; $\mathrm{W}_{\mathrm{K}}$ - scope of a shelter chamber, $\mathrm{m} 3 ; \mathrm{V} 1, \mathrm{~V} 1 \mathrm{x}$ - air velocity in a shelter opening and above source surface, $\mathrm{m} / \mathrm{s} ; \mathrm{Vo}$ - suction speed of gas-air mixture, $\mathrm{m} / \mathrm{s} ; \mathrm{cl}, \mathrm{c}$ - the average concentration of HCS in a room and in a shelter, respectively, mg/m3, cp - HCS concentration received from a shelter in a room, $\mathrm{mg} / \mathrm{m} 3$, at a distance $\mathrm{xp}$ from the opening, $\mathrm{m} ; \mathrm{h}$ - height of an opening, $\mathrm{m} ; \mathrm{z0}$ - exceeding the lower edge of an opening above HCS source surface with an equivalent diameter $\mathrm{d}, \mathrm{m}$.

When determining the parameters of the suction of a gas-air mixture, assumptions are made [1] that the air flow in the opening and the flow of the mixture are homogeneous, plane-parallel.

In a Cabinet shelter with a side suction of the mixture, the air speed in the lower part of an opening $\mathrm{V} 1 \mathrm{H}$ is less than the speed in its upper part $\mathrm{V} 1 \mathrm{~b}$ in $1,2 \ldots 1,3$ times when the height of the opening $h$ is more than $0.4 \mathrm{~m}$.

In the study of the effect of air velocity on heat source, the speed $\mathrm{V} 1 \mathrm{H}$ is used in 
processes of painting parts, drying them, electroplating, electrolysis, etc. for these processes, the volume of air L1 in relation to the air density $\rho b$ and gas-air medium $\rho \mathrm{cm}$ $\rho_{\mathrm{b}} / \rho_{\mathrm{cm}}>1$ is determined by the dependence [3] $L_{1}=\mu \cdot F_{\mathrm{pr}} \cdot \sqrt{2 \cdot g \cdot h \cdot\left(\rho_{\mathrm{b}} / \rho_{\mathrm{cm}}-1\right)}$, where $\mu \approx 0,75 \div 0,8$ - flow coefficient, Fpr - the area of an opening, $\mathrm{m} 2, \rho_{\mathrm{cm}}=$ $\left(L_{\mathrm{g}} \cdot \rho_{\mathrm{g}}+\rho_{\mathrm{b}} \cdot L_{1}\right) /\left(L_{1}+L_{\mathrm{g}}\right), \mathrm{kg} / \mathrm{m} 3, \mathrm{Lg}-$ volume of harmful gases released, m3/s, with density $\rho g$.

In some cases, $\mathrm{L} 1>>\mathrm{Lg}$ accepts $\rho \mathrm{cm} \approx \rho b$.

In contrast to the most commonly used upper flaps in cabinets to reduce the area of an opening Fpr [4] in a shelter scheme, the influence of exceeding value of the lower edge of an opening z0 on the decrease in air velocity above the surface of a source of HCS is studied.

At upper position of a leaf, air velocity above a source surface does not differ significantly from the velocity in upper part of an opening [1], which causes an intensification of HCS release.

Air velocity at the lower edge of an opening at its distance $r_{\mathrm{H}}=\sqrt{x_{\mathrm{o}}^{2}+\left(z_{1}-z_{\mathrm{o}}\right)^{2}}$ from slit suction B equal [3]

$$
V_{1}^{\mathrm{H}}=\frac{0,32 \cdot \mathrm{B} \cdot V_{\mathrm{O}}}{\sqrt{x_{0}^{2}+\left(z_{1}-z_{\mathrm{o}}\right)^{2}}} .
$$

At the top of an opening at a distance of $r_{\mathrm{B}}=\sqrt{x_{\mathrm{O}}^{2}+\left(z_{1}-z_{\mathrm{o}}-h\right)^{2}}$ air velocity is equal to

$$
V_{1}^{\mathrm{B}}=\frac{0,32 \cdot \mathrm{B} \cdot V_{\mathrm{O}}}{\sqrt{x_{\mathrm{o}}^{2}+\left(z_{1}-z_{\mathrm{o}}-h\right)^{2}}} .
$$

Taking into account these dependencies, average air velocity in a shelter opening is equal to $V_{1}=\frac{V_{1}^{\mathrm{H}}+V_{1}^{\mathrm{B}}}{2}$, the error of its determination does not exceed $5 \%$ when changing the height $\mathrm{h}=0,2 \div 1 \mathrm{~m}$.

Specific emissions of harmful substances my, mg/m $2 \cdot \mathrm{s}$, at their concentration at source surface cs and at free convection into air with a concentration c $\infty$ HCS, at mass transfer coefficient $\beta \mathrm{c}, \mathrm{m} / \mathrm{s}$, according to Dalton's law, are determined by dependence $m_{\mathrm{y}}=\beta_{\mathrm{c}}$. $\left(\mathrm{c}_{\mathrm{s}}-c_{\infty}\right)$. The concentration of HCS cs is determined by the Antoine equation $[5,6]$, in the absence of HCV in the air with $c_{\infty}=0$.

As a result of processing available experimental data on air velocity influence $\mathrm{V} 1 \mathrm{x}$ with temperature tB above a surface of source HCS in the range of speed $\mathrm{V} 1 \mathrm{x}=0,1 \div 1,0 \mathrm{~m} / \mathrm{s}$ and temperature $\mathrm{tB}_{\mathrm{B}}=10 \ldots 35^{\circ} \mathrm{C}[5,6]$ resulting figure $\varepsilon$ increasing selection $\mathrm{HCS} \varepsilon \cong(10,2+$ $\left.21,2 \cdot V_{1 \mathrm{x}}\right) / \sqrt{t_{\mathrm{B}}}$.

The specific allocation of HCS taking into account the indicator $\varepsilon$ will be equal

$$
m_{\mathrm{y}}=\beta_{\mathrm{c}} \cdot\left(c_{\mathrm{s}}-c_{\infty}\right) \cdot\left(10,2+21,2 \cdot V_{1 \mathrm{x}}\right) / \sqrt{t_{\mathrm{B}}} .
$$

When HCS is allocated to a limited volume of Cabinet shelter, the amount of HCS formation is affected by both free and forced convection. According to [7], mixed convection is determined by Nusselt criteria $\mathrm{Nu}=0,46 \cdot \sqrt{\mathrm{Re}+\sqrt{\mathrm{Gr} / 2}}$, Reynolds' $\operatorname{Re}=V_{1 \mathrm{x}} \cdot d / v$ and Grashof $\mathrm{Gr}=\frac{g \cdot d^{3} \cdot\left(t_{\mathrm{s}}-t_{\mathrm{z}}\right)}{273 \cdot v^{2}}$, where $v-$ viscosity of gas-air mixture, $\mathrm{m} 2 / \mathrm{s}$; ts, tc - temperature at HCS source surface and the average temperature in a shelter volume, ${ }^{\circ} \mathrm{C}$.

According to data [1], temperature difference in a shelter is proportional to 
concentration difference.

When the flow rate of released $\mathrm{HCS}, \mathrm{mg} / \mathrm{c}$, is equal to

$$
M=m_{\mathrm{y}} \cdot \pi \cdot d^{2} / 4,
$$

their average concentration in the volume of a shelter is equal to $c=M / L_{1}+c_{\mathrm{pr}}$, then

$$
t_{\mathrm{s}}-t_{\mathrm{c}}=\frac{\left[c_{\mathrm{s}}-\left(M / L_{1}+c_{\mathrm{pr}}\right)\right]}{\mathrm{c}_{\mathrm{s}}} \cdot t_{\mathrm{s}},
$$

where cpr - HCS concentration in air entering a shelter opening, $\mathrm{mg} / \mathrm{m} 3$.

Taking into account the above dependencies, the specific allocation of HCS is equal to

$$
m_{y}=0,46 \cdot D_{\mathrm{m}} \cdot \sqrt{\frac{V_{1 \mathrm{x}}}{v \cdot d}+\frac{1}{v} \cdot \sqrt{\frac{g \cdot d \cdot\left(t_{\mathrm{s}}-t_{\mathrm{c}}\right)}{273}}} \cdot\left(c_{\mathrm{s}}-c\right) \cdot\left(10,2+21,2 \cdot V_{1 \mathrm{x}}\right) \cdot \frac{1}{\sqrt{t_{\mathrm{B}}}},
$$

where Dm - coefficient of turbulent diffusion of HCS into the air, $\mathrm{m} 2 / \mathrm{s}$.

From the dependence (6) follows that in conditions of mixed convection, air velocity above the source surface significantly affects the release of HCS.

Air velocity in an opening and in the shelter according to [8-10] affects not only release of HCS, but also their arrival in a room. When air speed in an opening area V1 square Fn, consumption of allocated HCS M, distance of the source $i$ from the opening cp HCS at a distance xp determined by dependency

$$
c_{\mathrm{p}}=\frac{M}{F_{\mathrm{p}} \cdot V_{1}} \cdot i \cdot e^{-\frac{V_{1} \cdot x_{\mathrm{p}}}{A}},
$$

where A - coefficient of turbulent exchange, equal to $A=0,25 \cdot h^{1,33} \cdot\left[L_{1} \cdot V_{1}^{2} /\left(2 \cdot W_{\mathrm{K}}\right)\right]^{0,33}, \mathrm{~m} 2 / \mathrm{s}$.

Taking into account the dependencies (4), (7) and a shelter parameters shown in figure 1 , the dependence of determining the relationship of parameters is obtained V1, M, L1, cp and $\mathrm{xp}$

$$
\frac{c_{p}}{i \cdot\left(M / L_{1}\right)-\left(c_{1}+c_{\mathrm{pr}}\right) \cdot(1-i)}=\frac{V_{1} \cdot\left(x_{0}-x-x_{p}\right)}{A} .
$$

According to experimental data [1], the cpr concentration in composition of air entering a shelter with a flow rate of $\mathrm{L} 1$ is $30 \div 50 \%$ of the cp concentration determined by dependence (8) at a distance of $x p=0.3 \div 0.4 \mathrm{~m}$. the Remaining amount of HCS is assimilated by air supply in a room.

From the obtained dependencies, it follows that in order to determine effective mode of operation of local exhaust ventilation, it is necessary to determine measures to reduce harmful emissions formation by reducing air velocity from the value V1 to V1x. Its influence was investigated by experimentally determining air velocity in rarefaction zone behind a poorly streamlined barrier [3].

\section{Evaluation}

The experiments were performed using a ventilation system, a scheme of which is shown in figure 2 .

An adjustable electric heating device with a capacity of up to $2 \mathrm{~kW}$ is used as a convective source. By changing the height of the $z_{0}$ of a flat wall 6 in an opening, a decrease in air velocity over surface of heat source was determined at specified air velocity 
in an opening equal to $1.2 \mathrm{~m} / \mathrm{s}$.

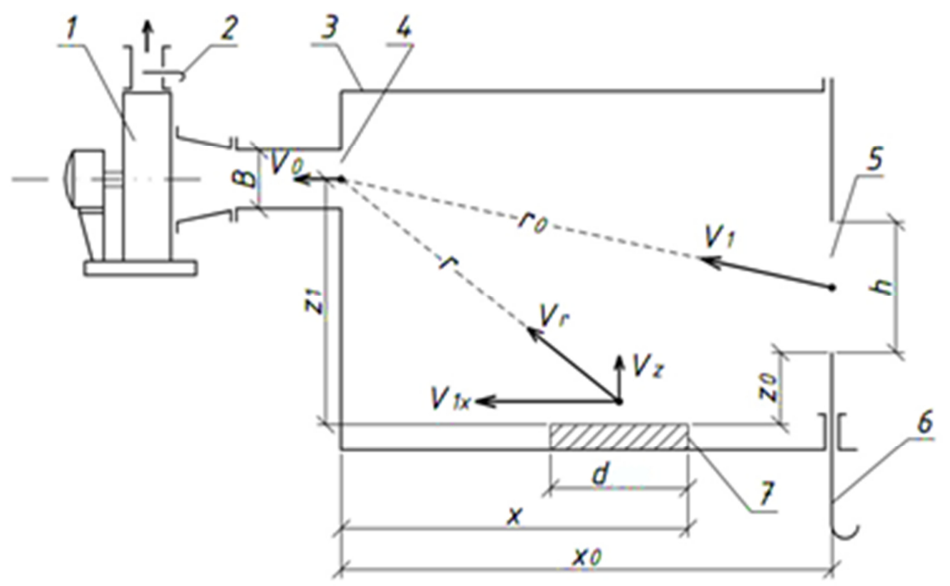

Fig. 2. Scheme of a ventilation unit with a shelter chamber: 1-fan, 2-gate, 3 - shelter chamber, 4suction hole, 5-technological opening of the shelter, 6-height-adjustable flat wall, 7-heat source.

Measurements of air velocity $\mathrm{Vr}$ were carried out at diameter of the heat source $d=0.2$ $\mathrm{m}$, with location of lower edge of the shelter opening at altitudes zo equal to $0,80,160,230$ and $300 \mathrm{~mm}$. The opening height of a chamber - shelter was $\mathrm{h}=0.4 \mathrm{~m}$, length (depth) of the shelter Ho $=0.6 \mathrm{~m}$, height of an air suction hole $\mathrm{z} 1=0.45 \mathrm{~m}$. Air was sucked out through a slotted hole $B=0.1 \mathrm{~m}$ wide in the flat wall of the shelter. At the position of the lower edge of the shelter opening at the level of the heat source surface, that is, at $\mathrm{zo}^{\mathrm{a}}=0$, the suction velocity $\mathrm{Vr}$ at a distance $\mathrm{r}$ and air velocityV1xp above source surface due to their slight change at a fixed source location were calculated taking into account the dependence [2] $V_{\mathrm{o}}=V_{\mathrm{r}} \cdot r /(0,3 \cdot B)$ and $V_{1 \mathrm{x}}^{\mathrm{p}}=V_{\mathrm{r}} \cdot \cos \gamma$, where $20 \mathrm{~s} \gamma=(x-d / 2) / r$.

Speed measurement was performed using the att-1004 thermal anemometer with an error of \pm 0.05 of the measured value.

The results of the measured parameters and calculations are shown in table 1.

Table 1. Results of experimental studies.

\begin{tabular}{|c|c|c|c|c|c|c|c|c|c|}
\hline & $\mathrm{z}_{0} . \mathrm{m}$ & $\begin{array}{l}\mathbf{r}_{0} . \\
\mathbf{m}\end{array}$ & r. $\mathbf{m}$ & $\mathbf{V}_{0} \cdot \mathbf{m} / \mathbf{s}$ & $\mathbf{V}_{\mathrm{r}} \cdot \mathbf{m} / \mathbf{s}$ & $\cos \gamma$ & $\begin{array}{l}V_{1 x}^{p} \\
\mathbf{m} / \mathbf{s}\end{array}$ & $\begin{array}{l}V_{1 x} \\
\mathbf{m} / \mathbf{s}\end{array}$ & $\begin{array}{c}V_{1 x}^{p} / \\
V_{1 x}{ }^{\exp }\end{array}$ \\
\hline \multirow{5}{*}{ 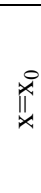 } & 0 & 0.65 & 0.56 & 24.4 & 1.42 & 0.89 & 1.25 & - & - \\
\hline & 0.08 & 0.63 & 0.56 & 23.6 & 1.40 & 0.89 & 1.24 & 0.25 & 5.6 \\
\hline & 0.16 & 0.62 & 0.56 & 23.2 & 1.32 & 0.89 & 1.17 & 0.25 & 4.7 \\
\hline & 0.23 & 0.61 & 0.56 & 22.9 & 1.30 & 0.89 & 1.16 & 0.30 & 3.9 \\
\hline & 0.3 & 0.6 & 0.56 & 22.5 & 1.28 & 0.89 & 1.14 & 0.30 & 3.8 \\
\hline \multirow{5}{*}{ 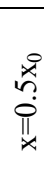 } & 0 & 0.65 & 0.32 & 24.4 & 2.42 & 0.62 & 1.50 & - & - \\
\hline & 0.08 & 0.63 & 0.32 & 23.6 & 2.40 & 0.62 & 1.48 & 0.30 & 5 \\
\hline & 0.16 & 0.62 & 0.32 & 23.2 & 2.32 & 0.62 & 1.44 & 0.35 & 4.1 \\
\hline & 0.23 & 0.61 & 0.32 & 22.9 & 2.30 & 0.62 & 1.42 & 0.42 & 3.4 \\
\hline & 0.3 & 0.6 & 0.32 & 22.5 & 2.25 & 0.62 & 1.40 & 0.43 & 3.2 \\
\hline \multirow{5}{*}{$\begin{array}{l}\stackrel{0}{x} \\
\stackrel{0}{0} \\
\stackrel{\|}{\| x}\end{array}$} & 0 & 0.65 & 0.26 & 24.4 & 3.10 & 0.31 & 1.00 & - & - \\
\hline & 0.08 & 0.63 & 0.26 & 23.6 & 2.90 & 0.31 & 0.90 & 0.60 & 1.5 \\
\hline & 0.16 & 0.62 & 0.26 & 23.2 & 2.85 & 0.31 & 0.88 & 0.61 & 1.4 \\
\hline & 0.23 & 0.61 & 0.26 & 22.9 & 2.80 & 0.31 & 0.87 & 0.63 & 1.38 \\
\hline & 0.3 & 0.6 & 0.26 & 22.5 & 2.76 & 0.31 & 0.86 & 0.68 & 1.26 \\
\hline
\end{tabular}


From the data obtained, it follows that the height of the lower edge of the shelter opening in the range of its change zo $=0.08 \div 0.3 \mathrm{~m}$ and the location of the compact source of harmful emissions $\mathrm{x} / \mathrm{xo}=0.3 \div 1.0$ reduce the air velocity above the source surface by $1.26 \div 5.6$ times. In accordance with the obtained dependence $(6)$, harmful secretions will be reduced by the same number of times.

For the specified values of the shelter parameters and the air entering it, figure 3 shows a graph of the change in the velocity ratio $V_{1 x} / V_{1}$ from the values zo and $x / x_{0}$.

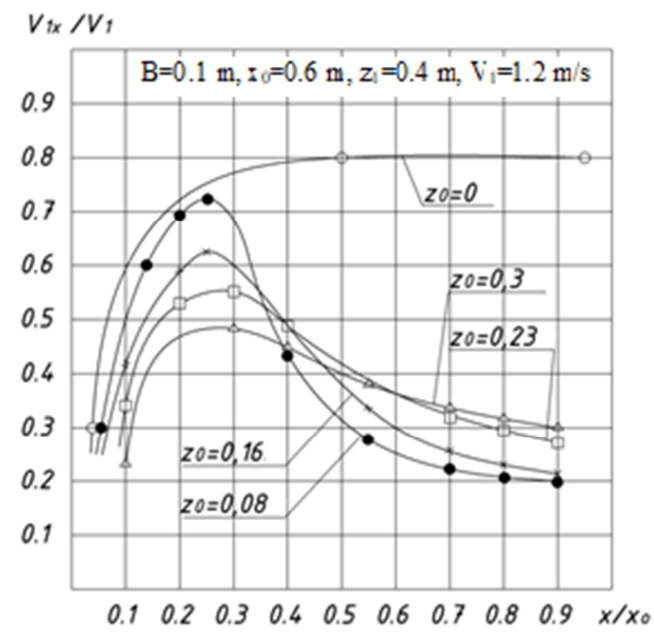

Fig. 3. The effect of the height of the zo wall in the opening and the location of the HCS $x / x_{0}$ source on air velocity $\mathrm{V}_{1 \mathrm{x}}$ above source surface.

From the data obtained, it follows that the greatest decrease in air velocity was observed near the opening, its decrease occurred at least four times, at a relative distance $\mathrm{x} / \mathrm{x} 0=0.25$, the speed decreased by $1.7 \ldots 2.4$ times. When the $\mathrm{x} / \mathrm{x} 0$ ratio is less than 0.1 , there is again a significant decrease in the air velocity above the source surface.

Using the experimental data obtained, the calculated dependence (8) is used to determine the distance $\mathrm{xp}$, where the HCS concentration in a room does not exceed the normalized value. Figure 4 shows the effect of changes in the amount of harmful emissions and the flow of incoming air to the shelter on the concentration of HCS in the room. These data show that when harmful secretions formation in the shelter decreases by up to $50 \%$, their concentration in a room also decreases proportionally. When air flow rate increases by 10 times, concentration in a room decreases three times.

Figure 5 shows the effect of the Cabinet cover volume Wk on change in concentration of HCS in a room.

From these data it follows that the increase in shelter with value $\mathrm{Wk}=1 \mathrm{~m} 3$ to $3 \mathrm{~m} 3$ reduces concentration in a room by $30 \ldots 35 \%$, a further increase in volume does not give meaningful results and leads to increased energy cost of ventilation due to the increased incoming air flow L1 in the shelter.

Therefore, the value of the cp concentration of harmful emissions in the service area of the local exhaust ventilation equipment depends on the amount of harmful emissions $M$, the amount of incoming air L1 from a room to the shelter, the height of the opening and its lower edge, the height of the gas-air mixture suction hole, and the location of the source of harmful emissions in the shelter.

In the installation shown in figure 2 Vhzexp air velocities are measured by the height of the shelter opening. Table 2 shows the values of the measured and calculated speeds in the shelter opening for the initial data: $\mathrm{xo}=0,6 \mathrm{~m}, \mathrm{zo}=0,05 \mathrm{~m}, \mathrm{~h}=0,4 \mathrm{~m}, \mathrm{~V} 1 \mathrm{~B}=1,2 \mathrm{~m} / \mathrm{s}$. 


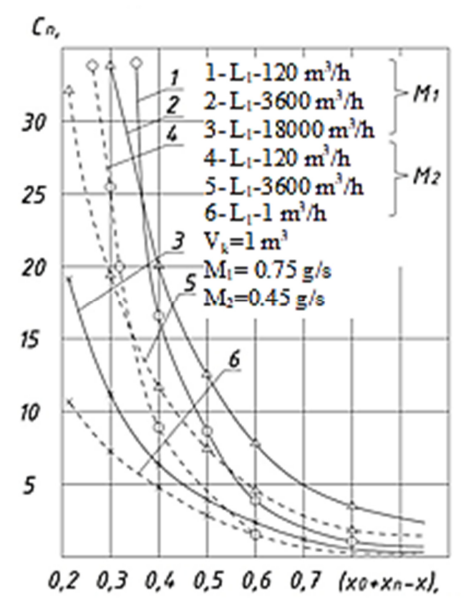

Fig. 4. The effect of HCS value and incoming air in the shelter on concentration in a room.

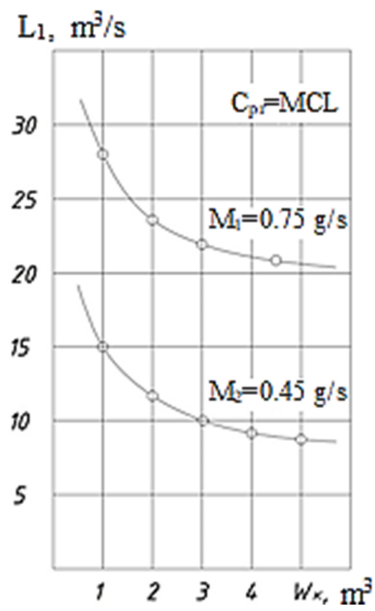

Fig. 5. The effect of the shelter volume, the amount of HCS and air on the complete prevention of HCS entering a room.

Table 2. Values of measured and calculated speeds in the shelter opening at the initial data.

\begin{tabular}{|c|c|c|c|c|c|c|c|c|c|c|}
\hline & \multicolumn{5}{|c|}{$\boldsymbol{z}_{1}=\mathbf{0 . 4 5} \mathbf{~ m}$} & \multicolumn{5}{c|}{$z_{1}=\mathbf{0 . 9} \mathbf{~ m}$} \\
\hline$\frac{h_{\mathrm{z}}-z_{0}}{x_{0}}$ & 0.58 & 0.42 & 0.25 & 0.08 & 0 & 0.58 & 0.42 & 0.25 & 0.08 & 0 \\
\hline$V_{\mathrm{hz}}^{\text {calc }}$ & 1.2 & 1.2 & 1.15 & 1.1 & 1.0 & 1.2 & 1.1 & 1.0 & 0.95 & 0.8 \\
\hline$V_{\mathrm{hz}}^{\text {calc }}$ & 1.2 & 1.2 & 1.1 & 1.1 & 0.9 & 1.2 & 1.1 & 1.0 & 1.0 & 0.9 \\
\hline
\end{tabular}

The obtained data indicate a satisfactory convergence of the calculated and experimental data on air velocity with the assumption that the flow in the opening of the shelter is plane-parallel.

\section{Conclusions}

The scientific novelty consists in the fact that to reduce the flow of gaseous harmful chemical emissions into a room and the amount of incoming air in the shelter of the Cabinet 
type of local exhaust ventilation by determining geometric parameters influence of the shelter on the amount of harmful emissions from their source. According to the obtained dependencies (6) and (8), the effect of the height of the lower edge of the opening of the Cabinet shelter on reducing the amount of harmful emissions from their source was determined. The degree of influence of source of harmful emissions location and the volume of the Cabinet shelter on the effectiveness of local exhaust ventilation were determined. According to the dependence (8), the value of average air velocity in the doorway of the Cabinet shelter, previously assigned according to toxicity of harmful secretions indicators, is specified.

\section{References}

1. A.Q. Ahmed, S. Gao, A.K. Kareem, Applied Thermal Engineering 1105, 821-834 (2017) DOI: https://doi.org/10.1016/j.applthermaleng.2016.08.217

2. V. Murgul, D. Vuksanovic, N. Vatin, V. Pukhkal, Applied Mechanics and Materials 680, 524-528 (2014) DOI: 10.4028/www.scientific.net/AMM.680.524

3. V. Pukhkal, N. Vatin, V. Murgul, Applied Mechanics and Materials 633-634, $1077-$ 1081 (2014). DOI: 10.4028/www.scientific.net/AMM.633-634.1077

4. V. Murgul, D. Vuksanovic, N. Vatin, V. Pukhkal, Applied Mechanics and Materials 635-637, 370-376 (2014) DOI: 10.4028/www.scientific.net/AMM.635-637.370

5. L. Tong, J. Gao, Z. Luo, et al., Building and Environment 149, 134-145 (2019) DOI: https://doi.org/10.1016/j.buildenv.2018.12.007

6. H.J. Rickenbacker, W.O. Collinge, V. Hasik et al., Sustainable Cities and Society 52, 101831 (2020) DOI: https://doi.org/10.1016/j.scs.2019.101831

7. T. Lehouillier, F. Soumis, J. Omer, C. Allignol, Computers \& Industrial Engineering 99, 269-279 (2016) DOI: https://doi.org/10.1016/j.cie.2016.07.025

8. V.G. Gagarin, K.I. Lushin, V.V. Kozlov, A.Y. Neklyudov, Procedia Engineering 1462016, 103-111 (2016) DOI: https://doi.org/10.1016/j.proeng.2016.06.359

9. T.C. Callari, N. McDonald, B. Kirwan, K. Cartmale, Safety Science 120, 838-849 (2019) DOI: https://doi.org/10.1016/j.ssci.2019.08.027

10. B. Yang, A.K. Melikov, A. Kabanshi et al., Energy and Buildings 2021, 109359 (2019) DOI: https://doi.org/10.1016/j.enbuild.2019.109359 